\title{
Soil-meteorological measurements at ICOS monitoring stations in terrestrial ecosystems
}

\author{
Maarten Op de Beeck ${ }^{1}$,Bert Gielen ${ }^{1}$, Lutz Merbold ${ }^{2,3}$, Edward Ayres ${ }^{4}$, Penelope Serrano-Ortiz ${ }^{5,6}$, \\ Manuel Acosta ${ }^{7}$, Marian Pavelka ${ }^{7}$, Leonardo Montagnani ${ }^{8,9}$, Mats Nilsson ${ }^{10}$, Leif Klemedtsson ${ }^{11}$, \\ Caroline Vincke $^{12}$, Anne De Ligne ${ }^{13}$, Christine Moureaux ${ }^{13}$, Sara Marañon-Jimenez ${ }^{14,15}$, Matthew Saunders ${ }^{16}$, \\ Simone Mereu ${ }^{17}$, and Lukas Hörtnagl ${ }^{2}$ \\ ${ }^{1}$ Department of Biology, University of Antwerp, Universiteitsplein 1, 2610, Wilrijk, Belgium \\ ${ }^{2}$ Institute of Agricultural Sciences, ETH Zürich, Universitätstrasse 2, 8092, Zürich, Switzerland \\ ${ }^{3}$ Mazingira Centre, International Livestock Research Institute (ILRI), P.O. Box 30709, 00100, Nairobi, Kenya \\ ${ }^{4}$ National Ecological Observatory Network, 1685 38th Street, Boulder, CO 80301, United States \\ ${ }^{5}$ Department of Ecology, University of Granada, 18071, Granada, Spain \\ ${ }^{6}$ Andalusian Institute for Earth System Research (CEAMA-IISTA), Universidad de Granada, 18006, Granada, Spain \\ ${ }^{7}$ Department of Matters and Energy Fluxes, Global Change Research Institute, Czech Academy of Sciences, Bělidla 986/4a, \\ 60300, Brno, Czech Republic \\ ${ }^{8}$ Faculty of Science and Technology, Free University of Bolzano, Piazza Universita' 1, 39100, Bolzano, Italy \\ ${ }^{9}$ Forest Services, Autonomous Province of Bolzano, Via Brennero 6, 39100, Bolzano, Italy \\ ${ }^{10}$ Department of Forest Ecology and Management, Swedish University of Agricultural Sciences, Skogsmarksgränd, 90183 , \\ Umeå, Sweden; \\ ${ }^{11}$ Department of Earth Sciences, University of Gothenburg, Guldhedsgatan 5a, 40530 Göteborg, Sweden \\ ${ }^{12}$ Université catholique de Louvain, Earth and Life Institute, Croix du Sud 2/L7.05.09, 1348 Louvain-la-Neuve, Belgium \\ ${ }^{13}$ University of Liège, Gembloux Agro-Bio Tech, TERRA, Ecosystems - Atmosphere Exchanges, Passage des Déportés 2 , \\ 5030 Gembloux, Belgium \\ ${ }^{14}$ Department of Applied Physics, University of Granada, 18071, Granada, Spain \\ ${ }^{15}$ CREAF, Cerdanyola del Vallès, 08193 Barcelona, Catalonia, Spain \\ ${ }^{16}$ Department of Botany, Trinity College Dublin, College Green, Dublin 2, Ireland \\ ${ }^{17}$ Centro Euro-Mediterraneo sui Cambiamenti Climatici, IAFES, via De Nicola 9, 07100, Sassari, Italy
}

Received January 10, 2018; accepted June 26, 2018

\begin{abstract}
The Integrated Carbon Observation System is a pan-European research infrastructure providing standardized, long-term observations of greenhouse gas concentrations and earthatmosphere greenhouse gas interactions. The terrestrial component of Integrated Carbon Observation System comprises a network of monitoring stations in terrestrial ecosystems where the principal activity is the measurement of ecosystem-atmosphere fluxes of greenhouse gases and energy by means of the eddy covariance technique. At each station a large set of ancillary variables needed for the interpretation of observed fluxes and for process studies is additionally monitored. This set includes a subset of variables that describe the thermal and moisture conditions of the soil and which are here conveniently referred to as soil-meteorological variables: soil temperature, volumetric soil water content, water table
\end{abstract}

*Corresponding author e-mail: maarten.opdebeeck@uantwerpen.be depth, and soil heat flux density. This paper describes the standard methodology that has been developped for the monitoring of these variables at the ecosystem stations.

Keywords: ICOS, soil temperature, soil water content, water table depth, soil heat flux density

\section{INTRODUCTION}

The Integrated Carbon Observation System (ICOS) is a distributed pan-European research infrastructure providing in-situ standardised, integrated, long-term and high-precision observations of lower atmosphere greenhouse gas (GHG) concentrations and land- and ocean-atmosphere GHG interactions. The terrestrial component of ICOS comprises a network of monitoring stations

(C) 2018 Institute of Agrophysics, Polish Academy of Sciences 
in terrestrial ecosystems where the principal activity is the measurement of ecosystem-atmosphere fluxes of GHGs and energy by means of the eddy covariance (EC) technique. At each station a large set of auxiliary variables needed for interpretation of the observed fluxes and for process studies is additionally monitored. This set includes a subset of variables that describe the thermal and moisture conditions of the soil and which are here conveniently referred to as soil-meteorological variables: soil temperature $\left(T S,{ }^{\circ} \mathrm{C}\right)$, volumetric soil water content $\left(S W C, \mathrm{~m}^{3} \mathrm{~m}^{-3}\right)$, water table depth $(W T D, \mathrm{~m})$, and soil heat flux density $\left(G, \mathrm{~W} \mathrm{~m}^{-2}\right)$.

$T S, S W C$, and WTD are measured at ICOS ecosystem stations to explain variation in measured fluxes, since they are known to be key drivers of ecosystem-atmosphere fluxes of GHGs and energy. For example, TS is known to drive the soil component of GHG fluxes through its effect on soil microbial activity and chemical reaction rates (Schaufler $e t$ al., 2010; Smith et al., 2003), while it affects also the vegetation component of these fluxes through its effect on plant root activity and water uptake (Jarvis and Linder, 2000; Pregitzer et al., 2000). SWC exerts control over soil GHG fluxes through its role in the supply of substrate for soil micro-organisms and its influence on gas diffusivity and oxygen availability in the soil (Howard and Howard, 1993; Huang et al., 2011; Smith et al., 2003). It also affects vegetation fluxes through drought-induced stomatal closure. WTD drives soil fluxes because it marks the depth of transition between the zones where the soil biochemistry is dominated by aerobic or anaerobic processes, which consume and produce GHGs at very different rates (Mikkelä et al., 1995; Smith et al., 2003; von Arnold et al., 2005). It also affects vegetation fluxes since root activity declines in the anoxic soil layer below the WTD (McDaniel, 2006) and because it determines the depth of the groundwater reservoir for plants in transpirational demand.

Soil heat flux density $(G)$ is measured at ICOS ecosystem stations to provide data for energy balance studies and for performance checks of the EC system by means of the energy balance closure. $G$ quantifies the flux of thermal energy released or taken up by the soil at its surface (Sauer and Horton, 2005) and is an important component of the short-term energy budget at the land surface, given by Eq. (1):

$$
R_{n}-G-S=L E+H,
$$

here: $R_{n}$ is net radiation, $G$ is the soil heat flux density, $S$ is the heat storage in biomass, air, water, or ice, $L E$ is the latent heat flux, and $H$ is the sensible heat flux. By closing the energy budget, i.e. by balancing the left- and right-hand side of Eq. (1), the quality of the (half-hourly averaged) daytime $L E$ and $H$ measured with the EC system can be assessed. An imbalance between the two sides may indicate inaccuracy in the measurements of $L E$ and $H$ if all other factors that may generate deviations in the energy balance closure are factored out (Foken, 2008; Metzger, 2018; Stoy et al., 2013; Wilson et al., 2002).
In this paper the standard methodology that has been developped for the measurement of these variables at ICOS ecosystem stations is described. This presented methodology is the result of a series of discussions within a dedicated working group composed of members of the scientific community contributing to ICOS and with expertise on soil monitoring at EC flux measurement sites. It has been translated in two practical instruction documents, aimed to be field guides for the station teams (Op de Beeck et al., 2017a, b), while in this paper the more general aspects of the methodology are explained.

\section{METHODOLOGY}

\section{Measurement methods and instrumentation}

The aims of the soil-meteorological measurements at ICOS ecosystem stations require continuous time series of high-quality soil-meteorological data with a minimum of data gaps. In order to guarantee this, all sensors employed in the field to collect these data need to fulfil a basic set of requirements. Employed sensors have to:

- allow unattended and automated measurements in the field,

- be designed for long-term burial in the soil,

- require minimal (re)calibration in the factory or the lab once installed, minimizing data gaps and soil disturbance due to sensor removal,

- have a fast enough response time to detect changes in the variable measured (within the recorded time interval),

- have a low susceptibility to drift,

- follow a well-validated measurement principle, and

- measure the target variable over its entire field range with a given minimal measurement accuracy (specific per variable).

This set of requirements has served as a basis to select for each variable one or more sensor types that are accepted within the ICOS ecosystem network:

- TS is measured with resistance temperature detectors, thermistors, or integrated circuit sensors. Selected sensors must have a measurement accuracy of $\pm 0.25^{\circ} \mathrm{C}$ or better (as indicated by the manufacturer in the sensor specifications) that is valid over the entire $T S$ range expected at the site where the sensors are installed.

- $S W C$ is measured with dielectric sensors: time domain reflectometers, frequency domain reflectometers, or amplitude domain reflectometers. Phase transmission and time domain transmission sensors are only accepted if their looped probe design does not lead to considerable soil disturbance during installation (Muñoz-Carpena et al., 2010). Selected dielectric sensors must have a measurement accuracy of $\pm 0.05 \mathrm{~m}^{3} \mathrm{~m}^{-3}$ or better under factory calibration (as indicated by the manufacturer in the 
sensor specifications), valid for the type of soil and over the entire $S W C$ range expected at the site where the sensors are installed.

- WTD is measured with submersible pressure transducers that are installed permanently in cased monitoring wells. To provide pressure measurements that are unaffected by changes in ambient atmospheric pressure, the transducers have to be gauged. Selected transducers must measure WTD - or better: water column height above the transducer - with a measurement accuracy of $\pm 0.5 \mathrm{~cm}$ or better that is valid over the entire range of water column heights expected in the wells where the transducers are installed.

- $G$ is measured with self-calibrating heat flux plates. Selected plates must have a measurement accuracy of $\pm 5 \%$ or better (as indicated by the manufacturer in the sensor specifications) over the entire range of $G$ expected at the site where the plates are installed. Only with self-calibrating plates this measurement accuracy can be reached, since the self-calibration allows to correct for errors resulting from differences between the thermal conductivity of the plates and the changing thermal conductivity of the soil and from thermal contact resistance (Ochsner et al., 2006). The only self-calibrating plate model currently available on the market and hence currently accepted within the ICOS ecosystem network is the HFP01-SC manufactured by Hukseflux (Hukseflux, 2011). Because heat flux plates must be buried a few centimetres below the surface, plate readings must be corrected for the change in heat storage in the soil layer above the plate. The change in heat storage is estimated with calorimetric calculations from measurements of TS and $S W C$ in the upper soil layer (see further). In addition to plate measurements, $G$ must in peat soils also be determined from measured temperature profiles in the upper soil layer (Laurila et al., 2012), applying the temperature gradient method (Kellner, 2001). This is because poor contact between the porous peat material and the plates can introduce significant error in the measurements (Halliwell and Rouse, 1987).

\section{Spatial sampling design}

Organisation of the measurements in the target area: soil plots

At each station, the soil-meteorological measurements are concentrated in a fixed number of spatial replicates that are distributed in the area targeted with the EC measurements. Put in other words, the soil is at a few locations around the EC measurement tower fully characterized in terms of its thermal and moisture conditions. These locations are here referred to as soil plots. In each soil plot, the four variables (TS, SWC, WTD and $G$ ) are measured on a continuous basis with sensors chosen by the station team from the accepted types described above.
The minimum number of soil plots that is installed at a station depends on the ecosystem type and on the station class and represents a trade-off between spatial coverage and feasibility. For stations in forests, croplands, and grasslands, the minimum number of soil plots is set to four for Class 1 stations (i.e. stations with highest level of standardisation) and two for Class 2 stations (stations with an intermediate level of standardisation). At stations in forests and croplands, each soil plot is located inside or at least very near a continuous measurements plot (CP), which is a permanent plot where repeated vegetation measurements are carried out (Gielen et al., 2018). This allows linking plot variation in vegetation growth to variation in soil conditions. At stations in grasslands, where no such CPs are installed, the location of the soil plots is decided by the station team, aiming at optimal coverage of the soil-meteorological conditions within the target area. This means that if the target area contains strata, i.e. areas with vegetation of distinct composition and structure that often reflect spatial differences in soil conditions, the soil plots are preferably distributed among the strata. For stations in mires, the minimum number of soil plots is a function of the number of plant community types that are distinguished in the target area and which are closely related to the microtopographical features present (hummocks, lawns, etc.) or to other strata present. For stations where one plant community type is identified, the minimum number of soil plots is four for Class 1 stations and two for Class 2 stations. For stations where two or more plant community types are distinguished and identified, the minimum number of soil plots in each community type is two and one, respectively. Each soil plot is located near one of the CPs that are installed in each plant community type for repeated vegetation measurements (Gielen et al., 2018). If physically possible and if not interfering with the measurements in the $\mathrm{CP}$, the soil plot is preferably installed in the same microtopographical unit as the $\mathrm{CP}$, e.g. in the same hummock. Otherwise, it is installed in the nearest similar microtopographical unit to the $\mathrm{CP}$.

Measurements in each soil plot

The measurements in each soil plot follow a standardized set-up. They are spaced horizontally such that that they do not interfere with each other but still relate to the same elemental volume of soil: depth profiles of $T S$ and $S W C$ are measured at horizontal distances of 30 to $45 \mathrm{~cm}$ on either side of the plate measurement of $G$, while the monitoring well for measurements of WTD is installed at a distance between 2 and $3 \mathrm{~m}$ away from the other measurements (Fig. 1). If using combined sensors for $T S$ and $S W C$, these sensors are all installed in a profile at one side of the plate. 


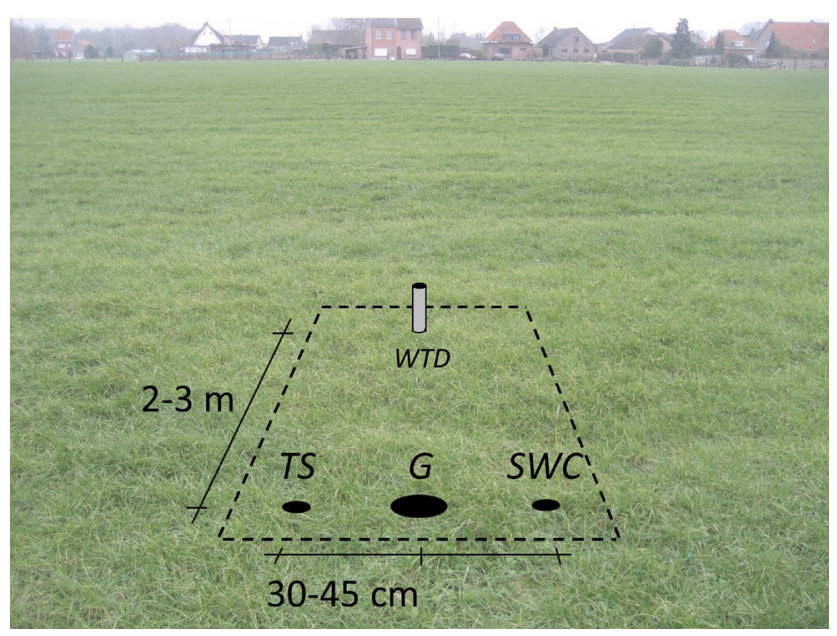

Fig. 1. Standard horizontal distances between measurements in a soil plot, shown explanatory for a grassland site, with locations of the vertical profiles of soil temperature (TS) and volumetric soil water content $(S W C)$, the soil heat flux density measurement $(G)$, and the monitoring well for measurements of water table depth (WTD).

(a)

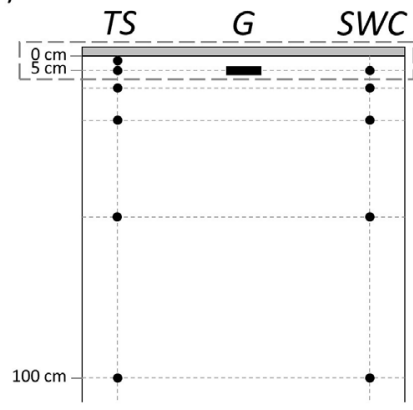

(c)

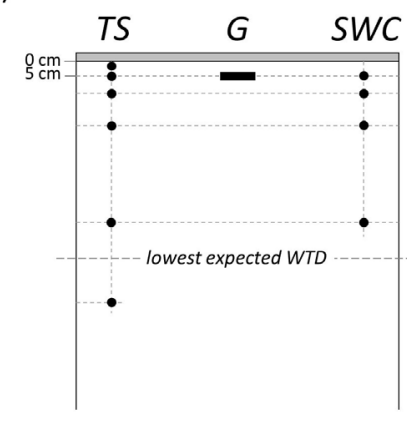

Measurement depths are always expressed as vertical distance to the local zero reference level and are negative above this level (Fig. 2). In mineral soils, the zero reference level is the boundary between the surface organic horizon, i.e. the O-horizon following the FAO definitions (FAO, 2006), and the underlying mineral horizon. If a surface organic horizon is not present, the zero reference level is the soil surface. In organic soils, such as found at monitoring stations in mires, the zero reference level is the top of the surface organic horizon, i.e. the $\mathrm{H}$ horizon following the FAO definitions (FAO, 2006).

- Soil temperature and soil water content: For practical reasons and because GHG fluxes are mainly driven by the thermal and moisture dynamics in the upper soil, the minimum depth of the $T S$ and $S W C$ profiles is set to $1 \mathrm{~m}$ (Fig. 2a). If limited by the presence of the bedrock or a water-impermeable layer, the profiles can be less deep (Fig. 2b). If measuring to a depth of $1 \mathrm{~m}$ or more, the $T S$ and $S W C$ profiles include at least six and five measurements, respectively (Fig. 2a). Less measurements per profile may suffice if measuring to a shallower depth (Fig. 2b-d). The uppermost TS measurement is done as

(b)

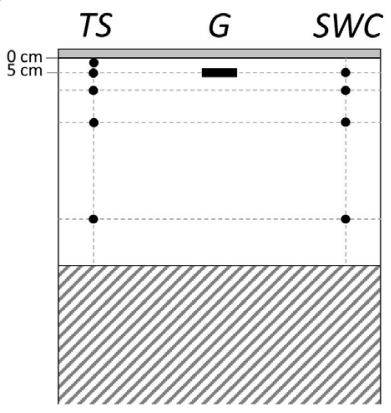

(d)

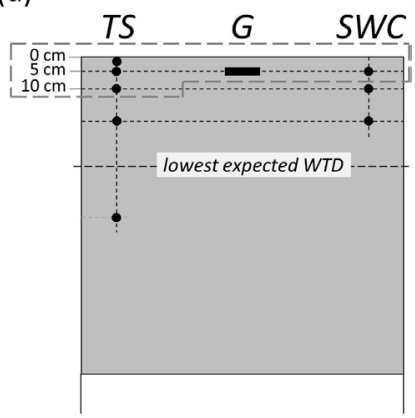

$\square$ organic $\square$ mineral $\square \mathbb{Z}$ bedrock / impermeable layer
set-up for additional heat flux plates at Class 2 stations

Fig. 2. Standard measurement depths in a soil plot. $T S=$ soil temperature, $S W C=$ volumetric soil water content, $G=$ soil heat flux density, and $W T D=$ water table depth. (a) Vertical profiles of $T S$ and $S W C$ are measured until a minimum depth of $100 \mathrm{~cm}$ and include at least six and five measurements, respectively, while $G$ is measured with a heat flux plate buried at $5 \mathrm{~cm}$ depth. (b) If limited by the presence of the bedrock or a water-impermeable layer, the $T S$ and $S W C$ profiles can be less deep and include less measurements. (c,d) SWC should not be measured below the lowest expected WTD, while TS may be measured below this depth to monitor the temperature in the permanently water-saturated soil layer. 


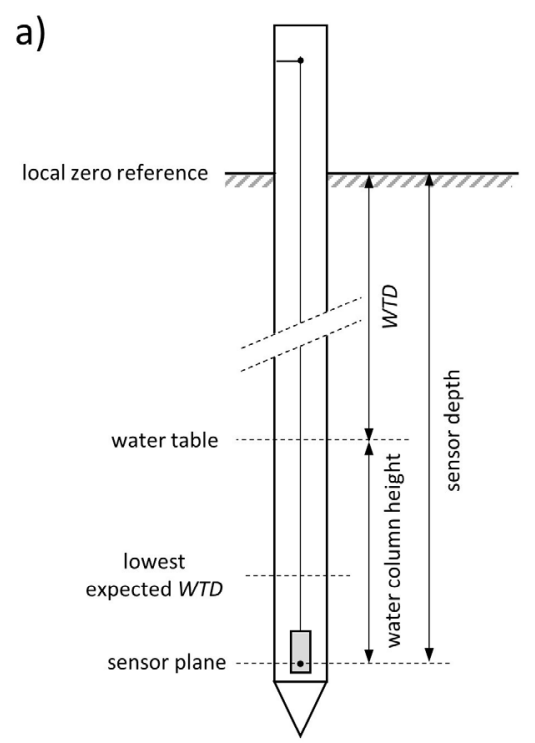

b)

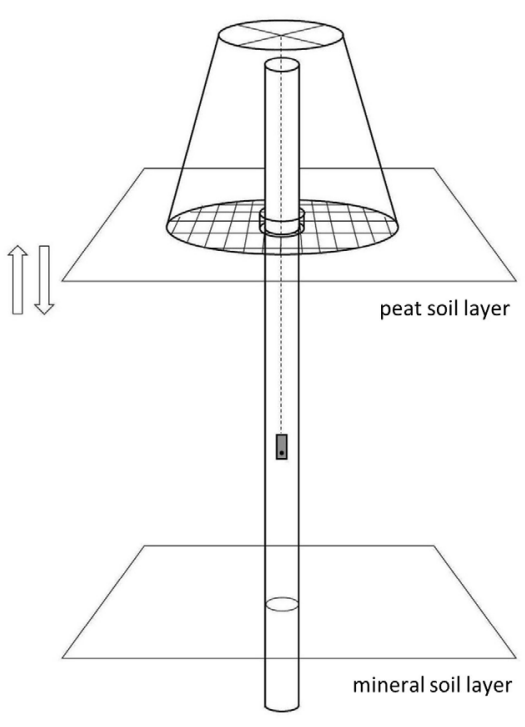

Fig. 3. (a) The measurement of water table depth (WTD) with a pressure transducer, and (b) conceptual design of a frame to be used at stations in mires. The frame moves up and down with the surface of the breathing peat layer, allowing to express measurements of $W T D$ done with the pressure transducer pending in the well from the frame relative to the moving peat surface.

close to the local zero reference level as possible, while the second TS measurement and the uppermost $S W C$ measurement are done at a fixed depth of $5 \mathrm{~cm}$. The other measurement depths are selected in function of the horizon profile and preferably follow a logarithmic distribution, i.e. the distance between two measurement depths increases with depth. If possible, it is recommended to follow the standard WMO depths of 10,20,50, and $100 \mathrm{~cm}$ (WMO, 2008). TS and $S W C$ are measured at the same depths whenever possible. Furthermore, $S W C$ should only be measured in the soil layer that is not permanently saturated with water and should hence not be measured below the lowest expected WTD. TS may be measured below this depth to monitor the temperature in the permanently water-saturated soil layer (Fig. 2c-d).

- Soil heat flux density: The heat flux plate for $G$ measurements is installed at $5 \mathrm{~cm}$ below the local zero reference level. This installation depth ensures good contact between the plates and the soil above and avoids that the plates are exposed to direct solar radiation. For the majority of soils, this installation depth furthermore limits the risk that the evaporation front penetrates the soil until below the plates and that the latent heat of evaporation is hence measured both belowground by the plates and aboveground by the EC system. In such case the latent heat would be counted twice in the surface energy budget (Heitman et al., 2008; Peng et al., 2017; Xiao et al., 2014; Zhang et al., 2012).

- Water table depth: The pressure transducers for WTD measurements are installed below the lowest expected WTD (Fig. 3a), except if this level is below the depth where the effect of WTD on the ecosystem is expected to be negligible. In this case, a depth below the rooting depth is proposed by the station team and discussed and agreed with the Ecosystem Thematic Centre (ETC), the central facility coordinating the ecosystem component within ICOS. If the seasonal high WTD falls below an accessible depth at which there is no effect of WTD on the ecosystem GHG fluxes, WTD should not be measured. At stations in mires, WTD has to be expressed relative to a soil surface that may move up and down due to peat swelling and shrinking. The pressure transducers therefore have to be pending in the well not from a point fixed to the monitoring well casing, as is usually done, but from a frame that can freely move up and down with the breathing peat and that is restricted in lateral movement. The conceptual design of such a frame is shown in Fig. 3b.

All measurements of a variable at a monitoring station are done with the same model of sensor. The TS and SWC profiles are established employing either single sensors installed at the prescribed depths or profile probes that have individual sensors built in at the desired distances. Because technical lower limits on sensor distances in commercially available probes might make it hard to find probes that can include the two uppermost $T S$ sensors, it is allowed to install TS profile probes that do not include the uppermost $T S$ sensor. In that case, a single $T S$ sensor must be installed as close as possible to the local zero reference level in order to complete the TS profile. This sensor may be a different model that the sensors built in the TS profile probe. If it is a different model, there must be installed also a single sensor of that model at $5 \mathrm{~cm}$ depth (Fig. 4). This is to ensure that the two TS measurements used to calculate heat storage corrections for the plate measurements of $G$ are done with the same sensor model. 


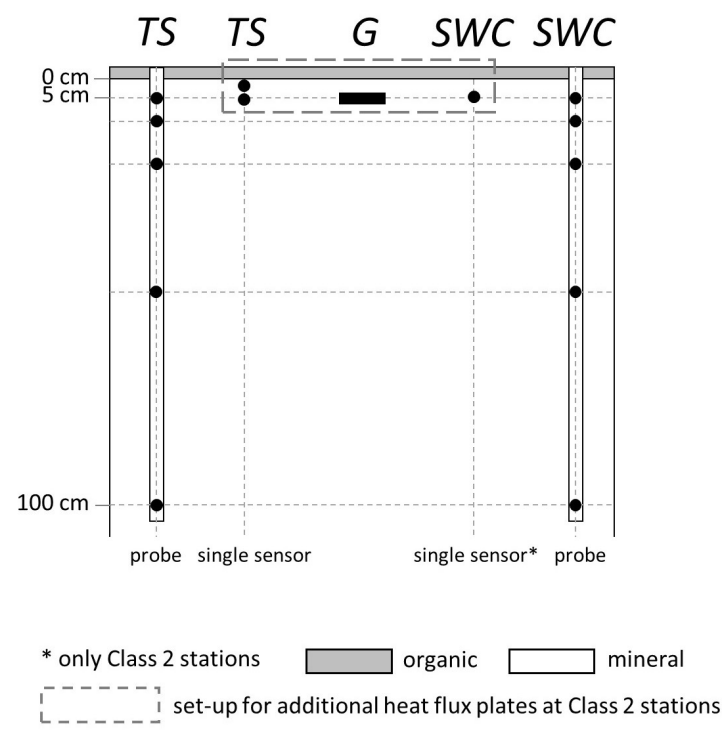

Fig. 4. Possible set-up of the measurements of soil temperature $(T S)$, volumetric soil water content $(S W C)$ and soil heat flux density $(G)$ in a soil plot where $T S$ and $S W C$ profile probes are installed. If the $T S$ profile probe does not include the uppermost TS measurement, a separate single $T S$ sensor is installed at the uppermost measurement depth. If this sensor is a different model than the sensors in the TS probes, a second single sensor of that model is also installed at $5 \mathrm{~cm}$ depth. At Class 2 stations where $S W C$ profile probes are installed in the soil plots, a separate single $S W C$ sensor is installed at $5 \mathrm{~cm}$ depth near the additional heat flux plates, and if this is a different model than the sensors in the profile probes, also near the heat flux plates in the soil plots.

At Class 2 stations in forests, croplands, and grasslands, where less than four soil plots are installed, additional heat flux plates are installed in the target area to bring the total number of soil heat flux density measurements in the target area to four at least. The additional plates are located such that all installed plates together provide optimal spatial coverage. This means that in open canopies plates must be installed both in canopy gaps and below vegetation and that, if the target area contains multiple strata with substantial contributions to the measured EC fluxes, plates must be distributed between the strata. Class 2 stations in mires with only one soil plot per plant community type are strongly advised to install at least one extra heat flux plate in each community type.

Each of the additional heat flux plates at Class 2 stations is installed in combination with two TS sensors - three at mire stations - and one $S W C$ sensor. These are installed at the same depths as the shallowest sensors of the TS and $S W C$ profiles (dashed boxes in Fig. 2a, d and Fig. 4). The output of these auxiliary sensors is used for the calculation of heat storage change in the soil layer above the plate, which is needed to correct $G$ measurements with the plate (see further). At Class 2 stations where the $T S$ and/or $S W C$ profiles in the soil plots are established employing profile probes, it is allowed to install auxiliary $T S$ and/or SWC sen-

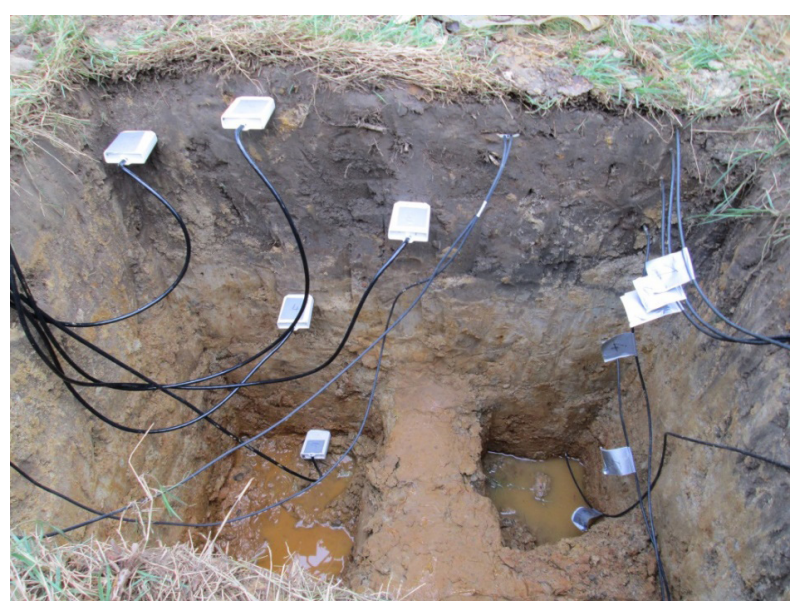

Fig. 5. Example of sensors installed in the wall of an excavated pit in a mineral soil at a candidate ICOS ecosystem station in a short rotation coppice culture with poplar (Lochristi, Belgium). Soil temperature sensors are installed along a vertical profile at 1.5, $5,10,20,50$, and $100 \mathrm{~cm}$ depth (right). Sensors for volumetric soil water content are installed along a vertical profile at 5, 10, 20, 50 , and $100 \mathrm{~cm}$ depth (left). The three upper sensors are not positioned on a vertical line but diagonally below each other in order to create enough distance to avoid mutual interference. The heat flux plate for the measurement of soil heat flux density is installed at $5 \mathrm{~cm}$ depth (middle).

sors near the additional plates that are a different model than the sensors built in the profile probes. In that case, single sensors of that model must be added to each soil plot for the two uppermost $T S$ measurements and/or the uppermost $S W C$ measurement (Fig. 4). This is to ensure that the $T S$ and $S W C$ measurements used to calculate heat storage corrections for the plate measurements of $G$ are for each installed plate done with the same sensor models.

As an example of the standard set-up, Fig. 5 shows the $T S, S W C$, and $G$ sensors installed in a soil plot in a mineral soil at a candidate ICOS ecosystem station in a short rotation coppice culture of poplar (Lochristi, Belgium). The sensors are installed in the wall of an excavated soil pit.

\section{Specific cases}

At stations where sensors have to be removed frequently, most notably croplands that are frequently visited by farm machinery, one permanent soil plot is installed in addition to the other soil plots. This permanent plot is located in an area where the engines do not roam, preferably the area immediately around the EC tower. This plot is a replication of the other soil plots, with the same number of sensors installed at the same depths. The sensors in the permanent plot are not removed during engine activity in the field and their output is used to fill the gaps in the data sets from the sensors in the field. Crop seeding/planting and harvesting and management practices are mimicked manually in this permanent plot. Furthermore, WTD is only measured in the permanent plot. The other soil plots should not include a monitoring well for WTD measurements. 


\section{Exceptions to the standard design}

The set-up of the soil plots at the ecosystems stations has to follow as much as possible the standard design described above, and this to guarantee harmonized and intercomparable measurements within the ICOS ecosystem network. However, some flexibility is allowed: if site particularities and notably practical issues make it difficult to implement the standard design in the field, deviations from the standard design in terms of soil plot locations and measurement distances can be allowed. Such exceptions to the standard design are always discussed and agreed between the station team and the ETC. One of the cases where an exception can be agreed is, to give an example, a station in a forest where motorized equipment is needed for drilling monitoring wells or digging soil pits and where such equipment is not permitted access in protected zones that include the CPs or is avoided access to the CPs in order avoid damage to vegetation. In this case, deviations from the standard soil plot locations can be discussed.

\section{Temporal sampling design}

The soil-meteorological variables are at each station measured year-round at high temporal resolution in order to assess the short-term variability as well as the long-term trends of the soil-meteorological conditions. The signal of each individual sensor is logged at $60 \mathrm{~s}$ intervals. Every measurement is recorded in physical units and, if available, also in raw instrument units. Measured data are transferred on a daily basis to the ETC, where they are subject to format checks and quality control routines, averaged over the same half-hour intervals as the EC flux measurements, gapfilled, and aggregated at temporal and spatial scales desired by the end users of the ICOS data products.

\section{Sensor calibration}

\section{Soil temperature}

The TS sensors can operate with the factory calibration and do not require any (initial) site-specific calibration. However, if quality control routines reveal long-term sensor drift, recalibration of the $T S$ sensors might be needed. This in fact applies to all soil-meteorological sensors.

\section{Volumetric soil water content}

The dielectric sensors selected for $S W C$ measurements are allowed to operate under factory calibration, yet a soilspecific calibration of the sensors at the start of the ICOS term is highly recommended, in particular for clayey and highly organic soils. A soil-specific calibration of the sensors will reduce measurement inaccuracy associated with the differences in soil bulk density, texture, and salinity between the soil in which the sensors are installed and the soils used for factory calibration. Within the ICOS ecosystem network, there is no fixed calibration procedure prescribed. Instead, a detailed calibration methodology is discussed and agreed between each station team and the ETC, taking into consideration the type of soil (mineral vs organic), the variability of the soil at the station, the sensor model to be calibrated, etc. Whatever the specificities of the methodology agreed, it always involves calibration of the sensors against gravimetric measurements of $S W C$ that are carried out on representative soil samples extracted from the field and that span the entire range of $S W C$ expected at the site where the sensors are installed (Dane and Topp, 2002; ISO, 2001). The calibration may be carried out on soil samples that are wetted to saturation in the lab and gradually let drying out, or vice versa (Campbell Scientific, 2012; Nagare et al., 2011; Quinones et al., 2003). Furthermore, the calibration may involve either establishing a unique calibration for each individual sensor that will be employed in the field, or else applying one calibration to multiple sensors, such as to sensors installed in the same soil horizon. These particularities are discussed between the station team and the ETC. The calibration procedure yields a set of data pairs of gravimetrically determined $S W C$ and raw sensor output, to which a linear or polynomial calibration curve is fitted.

\section{Water table depth}

The factory calibration of the pressure transducers is checked with a laboratory test prior to installation in the field (Freeman et al., 2004; Sinclair and Pitz, 2010). This test determines whether the instruments meet the manufacturer's accuracy requirement or not. Each pressure transducer is tested by inserting and withdrawing the transducer in a vertical standpipe that is kept filled to overflowing with water. The transducer readings are at five different, equally spaced depths compared with direct measurements of the water column height with a measurement tape. The range of submergence is equal or larger than the expected maximum water column height in the monitoring well where the transducer is installed. The laboratory test also includes a 'dry' measurement in air, for which the gauged transducers should give a zero reading (within accuracy range of the instrument). Additionally, a 'dry' variable-temperature test is performed in the lab, leaving the transducers to record while the air temperature fluctuates over a range that includes the range of groundwater temperature expected in the monitoring wells where the transducers are installed (Freeman et al., 2004). For temperature-compensated transducers the output during this test should not exceed the accuracy limits set for the compensated temperature range.

As an alternative to the laboratory test, the transducers can be subject to a field test after installation in the wells (Freeman et al., 2004). This field test is carried out in the first year of ICOS measurements and at the time of the highest seasonal $W T D$. The test is performed directly in the well by lowering and then raising the sensor by known increments and comparing transducer readings of water column height with manual measurements done with a steel tape, 
a sounder, or another manual device. The test measurements are done at a minimum of five levels equally spaced over the full water column range. At each level it is made sure that the transducer has equilibrated and, because moving the transducer cable in the water column displaces water in the well, that the water level has stabilized. The top of the well casing's riser pipe can be used as the reference for the direct measurement. The height of the riser pipe above the local zero reference level is subtracted from the direct distance measurement to obtain WTD.

Once the pressure transducers are installed in the field, $W T D$ is at each field visit (or at least biweekly) measured manually in each well with a steel tape, a sounder, or another manual device, and compared with the transducer measurements (Freeman et al., 2004). These accuracy checks are performed to document any potential transducer drift over time and in such case, the transducer is recalibrated.

\section{Soil heat flux density}

The selected plates for $G$ measurements are programmed to run a self-calibration once or twice per day. With each self-calibration, the calibration constant $E_{\text {sen }}$ that relates the heat flux density through the plate to the voltage output of the plate (Eq. (2)) is adjusted to the changing conditions in the soil:

$$
G_{\text {plate }}=\frac{V}{E_{\text {sen }}},
$$

where: $G_{\text {plate }}$ is the soil heat flux density at the depth of the plate, $V$ is the voltage output of the plate, and $E_{\text {sen }}$ is the calibration constant. The self-calibration routine involves generating a heat flux of known density by powering a film heater mounted on the upper side of the plate. A new value for $E_{s e n}$ is calculated such that the voltage response of the plate to the generated heat flux pulse agrees with the heat flux density through the plate that is expected if the thermal conductivities of soil and plate were perfectly matching. For details on the calculation, we refer to the HFPSC-01 Manual (Hukseflux, 2011). The heating of the plate temporarily affects the plate readings; it takes some time until the effect of the heating on the measured soil heat flux has disappeared. The length of this 'cooling period' is variable and depends on how fast the energy generated during the heating step dissipates in the soil. This varies with soil type and soil water content and is hence very site-specific. Therefore, measurements of $G_{\text {plate }}$ during the cooling period are not representative. Whether plates have to be calibrated once or twice per day depends on the average duration of one self-calibration, i.e. from the start of the heating until the heating effect on the measured heat flux density has fully disappeared. The calibration of the plates at a station is timed such that only one plate is calibrated at the time and that the calibration window is for each plate shifted one hour every day. Measurements during self-calibrations are omitted from final data sets.
In soils where the self-calibrations do not produce satisfying results or where it takes very long for the effect of the plate heating to disappear - and an unacceptably large number of data hence has to be discarded -, it can be opted to perform a manual calibration of the plate following procedures that are agreed between the station team and the ETC. Such a calibration involves measurements that allow expressing $E_{\text {sen }}$ as a function of $S W C$, the latter being the most important driver of the short-term variability of the thermal conductivity of the soil.

\section{Maintenance}

Once installed in the soil, the TS and SWC sensors and the heat flux plates do not require specific maintenance. For pressure transducers, the only specific maintenance involves the timely replacement of the desiccant unit that might be used to keep the vent tube dry. As a general maintenance routine, all soil plots are visited on a frequent basis for early detection of possible disturbances, including damage from wildlife, vandalism, roaming scientists, and, in grazed grasslands, livestock. Also the surfacing power and data cables running from soil plots to data loggers are checked at each visit. Furthermore, the monitoring wells are checked for unwanted objects inside the well (insects, etc.). The height of the riser pipe of the wells is checked after and during periods of frost, because freeze-thaw processes create 'frost heaving' and can jack wells from the ground, changing the position of the well casing relative to the local zero reference level. This may lead to displacement of the transducer if it is suspended in the well from a hanging point fixed to the well casing. At each visit, also the connection of the suspension cable to the hanging point in the well is checked, since the cable may be prone to slipping. Since ice formation on the sensor diaphragm will irreparably damage the sensor, the pressure transducers are removed from the monitoring wells at stations in cold climate zones at times when ice formation in the well is expected. The instruments are reinstalled after thawing. At mire sites, sensor depths are checked at the start and the end of each growing season, as the distance of the sensors to the local zero reference level changes in time due to the continuous accumulation of organic material at the soil surface. The position of the sensors is adjusted if needed.

\section{Calculations}

The output of each sensor is averaged to half-hourly means from all 30 measurements in the half hour interval with:

$$
\bar{X}=\frac{\sum_{i=1}^{30} x_{i}}{30},
$$

where: $\bar{X}$ is the half-hourly mean and $x_{i}$ are the individual measurements. Heat flux density measurements from the plate are first corrected for the change in heat storage in 
the soil layer above the plate before being averaged. This change $\left(\Delta S, \mathrm{~W} \mathrm{~m}^{-2}\right)$ is calculated with the calorimetric method:

$$
\Delta S=\Delta z C_{s}\left(\frac{\Delta T S}{\Delta t}\right)
$$

where: $\Delta z$ is the thickness of the soil layer between the plate and the zero reference level $(0.05 \mathrm{~m}), C_{s}$ is the volumetric heat capacity of that soil layer $\left(\mathrm{J} \mathrm{m}^{-3}{ }^{\circ} \mathrm{C}^{-1}\right)$, and $\Delta T S / \Delta t$ is the temperature change over $\Delta t(60 \mathrm{~s})$. The temperature change $(\Delta T S)$ is the difference between the current temperature measurement (at time $t$ ) and the previous temperature measurement (at time $t-1=t-60 \mathrm{~s}$ ):

$$
\Delta T S=T S_{t}-T S_{t-1},
$$

here, soil temperature $\left(T S_{x}\right)$ is the average of the temperature read by the two upper TS sensors, i.e. the sensor installed just below the zero reference level and the sensor at $5 \mathrm{~cm}$ depth.

The volumetric heat capacity of the soil $\left(C_{s}\right)$ is the sum of the specific heat capacities of its constituents: soil minerals $(\mathrm{sm})$, organic matter $(o)$, water $(w)$, and air $(a)$. The specific heat capacity of air is negligible compared to the other constituents, so $C_{s}$ can be calculated with (de Vries, 1963):

$$
C_{s}=\phi_{s m} \rho_{s m} \theta_{s m}+\phi_{o} \rho_{o} \theta_{o}+\phi_{w} \rho_{w} S W C,
$$

here, $\phi$ is the specific heat per unit mass $\left(\mathrm{J} \mathrm{g}^{-1}{ }^{\circ} \mathrm{C}^{-1}\right)$ and $\rho$ is density $\left(\mathrm{g} \mathrm{m}^{-3}\right)$. Values for $\phi$ and $\rho$ are given in Table 1. $\theta_{s m}$ and $\theta_{o}$ are the volume fractions of soil minerals and organic matter $\left(\mathrm{m}^{3} \mathrm{~m}^{-3}\right.$ soil), and $S W C$ is the volumetric soil water content measured with the $S W C$ sensor at $5 \mathrm{~cm}$ depth. In soils containing no or very few organic matter, Eq. (6) can be simplified to:

$$
C_{s}=\phi_{s m} x+\phi_{w} \rho_{w} S W C,
$$

where: $x$ is the bulk density of the soil $\left(\mathrm{g} \mathrm{m}^{-3}\right)$. In highly organic soils with no or few soil minerals, Eq. (6) can be simplified to:

$$
C_{s}=\phi_{o} \rho_{o} \theta_{o}+\phi_{w} \rho_{w} S W C .
$$

The volume fractions of soil minerals and organic matter can be considered time invariant.

Table 1. Physical properties of soil constituents: specific heat capacity $(\phi)$, density $(\rho)$ and thermal conductivity $(\lambda)$

\begin{tabular}{lccc}
\hline Soil constituents & $\begin{array}{c}\phi \\
\left(\mathrm{J} \mathrm{g}^{-1}{ }^{\circ} \mathrm{C}^{-1}\right)\end{array}$ & $\begin{array}{c}\rho \\
\left(10^{6} \mathrm{~g} \mathrm{~m}^{-3}\right)\end{array}$ & $\begin{array}{c}\lambda \\
\left(\mathrm{W} \mathrm{m}^{-1}\right. \\
\left.{ }^{\circ} \mathrm{C}^{-1}\right)\end{array}$ \\
\hline Soil minerals (sm) & 0.87 & 2.65 & \\
Organic matter (o) & 1.92 & 1.30 & 0.25 \\
Water (w) & 4.18 & 1.00 & 0.57 \\
Air (a) & & & 0.025 \\
\hline
\end{tabular}

Values are taken from Campbell and Norman (1998).
Then the heat flux density measured with the plate ( $\left.G_{\text {plate }}\right)$ is corrected with $\Delta S$ to obtain the soil heat flux density at the zero reference level $(G)$ :

$$
G=G_{\text {plate }}+\Delta S .
$$

Half-hourly $G$ means are then calculated with Eq. (3) from all 30 values of $G$ in the half-hour interval.

At stations in mires, $G$ is also calculated from the output of the three upper $T S$ sensors with a combination of the temperature gradient method and the calorimetric method. First, the heat flux density at a depth $z\left(G_{z}\right)$ is calculated with the temperature gradient method using measurements of the first and third temperature sensor in the TS profile:

$$
G_{z}=-\lambda \frac{\left(T_{3-}-T_{1}\right)}{\left(z_{3}-z_{1}\right)},
$$

where: $T_{3}$ is the measurement from the third sensor, installed at depth $z_{3}(=10 \mathrm{~cm})$ and $T_{1}$ is the measurement from the first sensor, installed at depth $z_{1}$ (just below the local zero reference level). The reference depth $\mathrm{z}$ is the midlayer depth between $z_{1}$ and $z_{3}$ (= approx. $5 \mathrm{~cm}$ ). The thermal conductivity of the soil $(\lambda)$ is calculated from the thermal conductivities of the different soil fractions. In the highly organic peat soils, which only have a small or negligible mineral fraction, $\lambda$ can be estimated with (Kellner, 2001):

$$
\lambda=\theta_{a} \lambda_{a}+\left(\theta_{o}+S W C\right) \lambda_{s}{ }^{\left(\theta_{0} /\left(\theta_{0}+S W C\right)\right)} \lambda_{w}{ }^{\left(S W C /\left(\theta_{0}+S W C\right)\right)},
$$

here: $\lambda_{x}$ is thermal conductivity of the soil constituents, for which values are given in Table 1 . The variables $\theta_{a}$ and $\theta_{o}$ are the volume fractions of air and organic matter $\left(\mathrm{m}^{3} \mathrm{~m}^{-3}\right.$ soil), respectively, and $S W C$ is volumetric soil water content measured with the dielectric sensor at $5 \mathrm{~cm}$ depth. $\theta_{a}$ can be calculated from soil porosity $(n, \%)$ and $S W C$ :

$$
\theta_{a}=\frac{n}{100}-S W C .
$$

The change in heat storage in the soil layer above depth $z(\Delta S)$ is calculated with the calorimetric method using Eqs (4) to (8). Instant soil heat flux density $(G)$ and halfhourly average $(G)$ are calculated with Eqs (13) and (3), respectively:

$$
G=G_{z}+\Delta S .
$$

Data on soil structural and compositional properties needed to calculate $G$ are provided by - or can be derived from - results of the soil sampling campaigns that are at each station carried out during the establishment of the ICOS ecosystem station.

\section{Data quality control}

The measurements from all stations are centrally, at the ETC, subjected to a common set of automated, near real-time quality control (QC) routines for detection of non- 
sensical or suspicious sensor output. The QC furthermore includes quality checks on long-term data series to detect possible sensor drift. The automated QC tests evaluate the quality of the soil-meteorological data at various levels of aggregation, starting from the high-frequency single-sensor data that arrive at the ETC. They include, among others, range tests to evaluate whether single data values fall within established plausibility limits, step tests to detect spikes and zero changes, persistency tests to evaluate whether the variability of the measurements over a certain time interval falls within realistic or acceptable upper and lower limits, and consistency tests that evaluate the variable against other independently assessed variables on the basis of welldefined empirical or theoretical relationships. The latter tests involve both quantitative and qualitative relationships and range from very simple to very complex (modelling). Examples are the comparison of plate measurements of $G$ with values estimated from the measured soil temperature gradient in the upper soil layer and the evaluation of $S W C$ changes in the upper soil layer against rainfall data. The limits and thresholds for QC tests are first set arbitrarily but, in order to decrease the number of false positives and negatives, in a next phase adjusted by training the test algorithms in an automated fashion using the data from the sensors. The QC routines also include tests that evaluate e.g. temperature effects on WTD and $S W C$ readings. For these tests, temperature readings of the transducers and $T S$ measurements collected within each soil plot at the same depths as $S W C$ will be used. A full description of the QC routines falls outside the scope of this paper and will be treated separately.

\section{Final data set}

As an example, Fig. 6 shows time series of the soilmeteorological measurements collected in a soil plot installed in a mineral soil at a candidate station in a short rotation coppice culture of poplar (Lochristi, Belgium, Fig. 5). These measurements have been subjected to a basic manual quality check only, not to the extensive, automated QC routines that ICOS data undergo. While these time series demonstrate the finest temporal and spatial scale at which soil-meteorological data are available to the end users of ICOS data, also site-averaged values of the variables at larger timescales (e.g. daily and monthly averages) are made publicly available to the end users. Data users also have access to metadata on the employed sensors (model, manufacturer, location, calibration, and calibration method), as well as information on soil characteristics (horizon profile, soil composition, texture, and structure).

\section{RESULTS AND DISCUSSION}

Soil-meteorological variables are known to drive the fluxes of GHGs and energy between ecosystems and the atmosphere (Schaufler et al., 2010; Smith et al., 2003). Temperature and moisture levels of the soil have moreover been shown to be directly impacted by climate change through rising air temperature and altered precipitation patters (Gerten et al., 2007; Jungqvist et al., 2014; Kurylyk et al., 2014). Measuring these variables at ICOS ecosystem stations is hence essential for explaining and interpreting observed variability in monitored ecosystem-atmosphere fluxes in a changing climate. The standardisation of the methodology to measure these variables, as well as of the methods to evaluate the quality of the collected data, enhances harmonization and the intercomparability of data from the multiple stations in the ecosystem network.

A key component of the standard methodology involves the employment of a common set of sensors or measurement techniques at all stations within the ICOS ecosystem network. For each soil-meteorological variable one or more sensors/techniques that are deemed most fit to fulfil the needs of the ICOS ecosystem network have therefore been
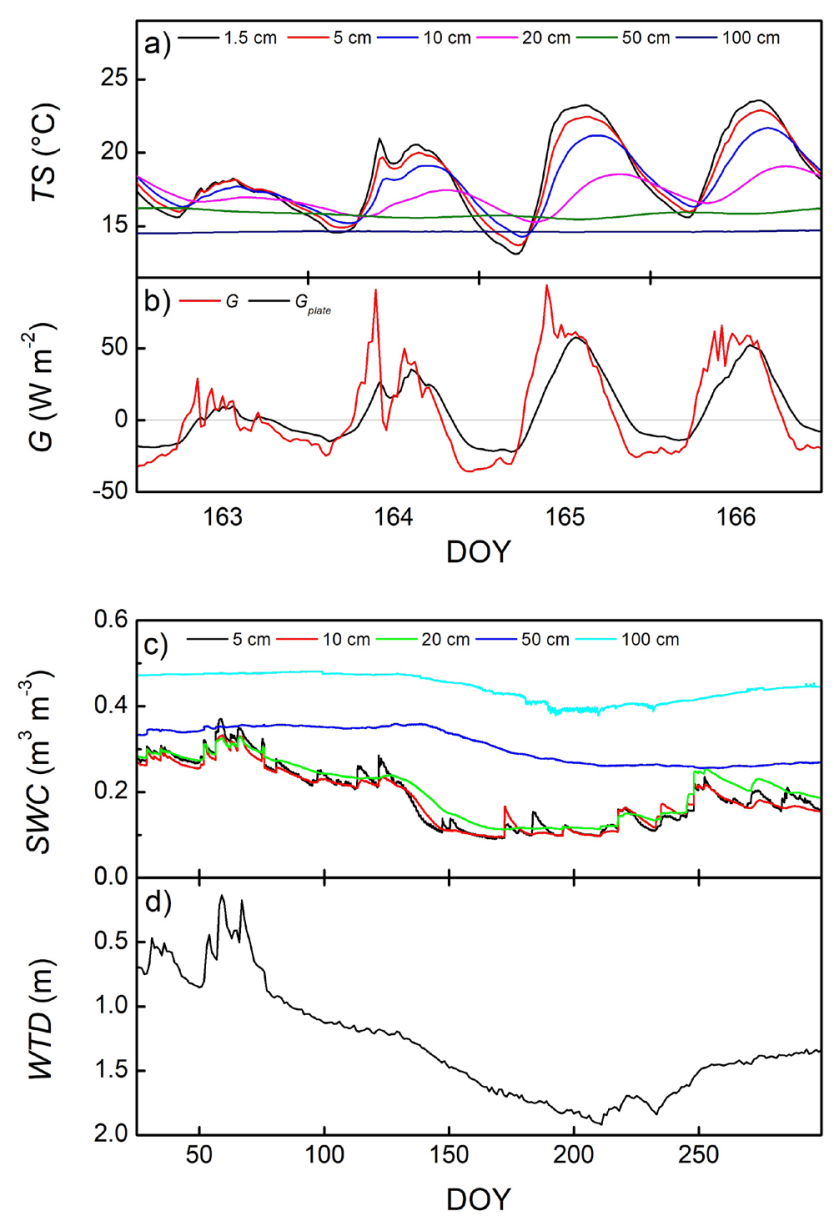

Fig. 6. Time series of half-hourly averaged measurements from a soil plot installed in a mineral soil at a candidate ICOS ecosystem station in a short rotation coppice culture of poplar (Lochristi, Belgium; see also Fig. 5). The two upper panels show a fourday period in early summer 2017 with time courses of (a) soil temperature (TS) and (b) soil heat flux density measured with the plate $\left(G_{\text {plate }}\right)$ and soil heat flux density at the soil surface $(G)$. The two lower panels show (c) volumetric soil water content $(S W C)$ and (d) water table depth $(W T D)$ for the period FebruaryOctober 2017. 
selected from the wide range of sensors/techniques available. For example, $S W C$ has to be measured with dielectric sensors within the ICOS ecosystem network. These sensors allow for automated, continuous measurements of $S W C$ at predefined depths and are therefore preferred over other continuous sensors/techniques, such as neutron probes, the gamma ray absorption technique, ground penetrating radar, and heat pulse/dissipation sensors (Muñoz-Carpena et al., 2010). Measurements of WTD have to be collected with gauged pressure transducers installed in cased monitoring wells. Pressure transducers provide an easy and accurate way to monitor $W T D$ and are preferred over other continuous WTD devices, such as float recorder systems and ultrasonic or acoustic resonance sensors. The former are, unlike transducers, susceptible to mechanical failure and require relatively large monitoring hole diameters. The latter are, unlike transducers, sensitive to humidity and they are rather costly (IGRAC, 2008). Measurements of $G$ have to be collected with heat flux plates, which are commonly employed for surface energy balance applications. Heat flux plates are preferred within the ICOS ecosystem network over other measurement methods, such as the calorimetric method and the temperature method, because plates provide a direct measurement of $G$, after a correction for the heat storage change in the soil layer above the plate, while the other techniques require detailed information on soil thermal properties that may not be readily available.

Furthermore, the standard methodology provides the station teams with detailed installation guidelines for all sensors to avoid or minimize errors associated with improper installation (Op de Beeck et al., 2017a, b), and other measures to deal with the errors that are unavoidably associated with the measurement of the soil-meteorological variables with the prescribed sensors/techniques. These measures and guidelines aim at treating errors similarly for all ecosystem stations and minimizing them where possible. Also, the soil-meteorological measurements from all stations are centrally, at the ETC, subjected to a common set of near real-time quality control routines for detection of non-sensical or suspicious sensor output, enabling to act swiftly in case of sensor malfunctioning, and to quality checks on long-term data series to detect possible sensor drift.

The standard methodology as presented in this paper will be kept up to date with future developments in measurement sensors and techniques. This means that the methodology explained in this paper will be re-evaluated towards the end of the lifetime of the sensors that are now being installed and employed at the ICOS ecosystem stations, and that new sensors or techniques may be included in addition to, or as replacement of, those currently accepted. To give one example, it may be worth considering in a future iteration of the standard methodology the inclusion of multi-needle heat pulse probes for the measurement of soil heat flux density. These probes make simultaneous measurements of the temperature gradient and the soil ther- mal conductivity and allow direct calculation of soil heat flux by the temperature gradient method (Bristow et al., 1994). They have been successfully employed to measure $G$ in a limited number of studies (Cobos and Baker, 2003; Ochsner et al., 2006; Peng et al., 2017). An advantage of heat pulse probes over plates is that they are less intrusive and do not block vertical transfer of water. After more intensive testing, heat pulse probes may be considered as an alternative or successor to heat flux plates.

\section{CONCLUSIONS}

1. Continuous measurements of soil-meteorological variables are indispensable for explaining and interpreting variability of ecosystem-atmosphere fluxes of greenhouse gases and energy that are monitored at ecosystem stations in the Integrated Carbon Observation System.

2. The standardisation of the methodology to collect soil-meteorological data and the methods to evaluate the quality of the collected data enhances harmonization and the intercomparability of data from the multiple stations in the ecosystem network.

3. The standard methodology for soil-meteorological measurements as described in this paper will be kept up to date with future developments in measurement sensors and techniques, and new sensors may be considered for inclusion in future iterations of the methodology.

\section{ACKNOWLEDGMENTS}

Maarten Op de Beeck and Bert Gielen were supported by the FWO-Flanders. Lutz Merbold and Lukas Hörtnagl acknowledge funds received under the Swiss National Science Foundation-funded project ICOS-CH (grant agreements 20FI21_148992, 2013- 2017 and 20FI21_173691, since 2017) and of ETH Zurich (0-23184-15 grant agreements 20FI21_148992, 2013- 2017 and 20FI21_173691, since 2017). Ed Ayres acknowledges the National Ecological Observatory Network, which is sponsored by the US National Science Foundation and managed under cooperative agreement by Battelle Ecology, Inc. This material is based upon work supported by the US National Science Foundation (grant DBI-1638696; 2016-2020). Any opinions, findings, and conclusions or recommendations expressed in this material are those of the author and do not necessarily reflect the views of the US National Science Foundation. The authors are grateful to Daniela Franz for revision of the manuscript.

Conflict of interest: The Authors declare no conflict of interest.

\section{REFERENCES}

Bristow K.L., Kluitenberg G.J., and Horton R., 1994. Measurement of soil thermal properties with a dual-probe heat-pulse technique. Soil Sci. Soc. Am. J., 58, 1288-1294. 
Campbell G.S. and Norman J.M., 1998. An Introduction to Environmental Biophysics. Springer-Verlag, New York, USA.

Campbell Scientific, 2012. CS650 and CS655 Water Content Reflectometers Instruction Manual. Revision: 10/12.

Cobos D.R. and Baker J.M., 2003. In situ measurement of soil heat flux with the gradient method. Vadose Zone J., 2, 589-594.

Dane J.H. and Topp G.C., 2002. Methods of Soil Analysis: Part 4 Physical Methods. Soil Science Society of America, Inc., Madison, USA.

de Vries D.A., 1963. Thermal properties of soils. In: Physics of Plant Environment (Ed. W.R. van Wijk). North-Holland Publishing Company, Amsterdam, The Netherlands.

FAO, 2006. Guidelines for Soil Profile Description and Classification (Eds R. Jahn, H.-P. Blume, V.B. Asio, O. Spaargaren, P. Schad) (Contributors R. Langohr, R. Brinkman, F.O. Nachtergaele and P. Krasilnikov), FAO, Rome.

Foken T., 2008. The energy balance closure problem - an overview. Ecol. Appl., 18, 1351-1367.

Freeman L.A., Carpenter M.C., Rosenberry D.O., Rousseau J.P., Unger R., and McLean J.S., 2004. Use Of submersible pressure transducers in water-resources investigations. Chapter A of Book 8, Instrumentation, Section A, Instruments for Measurement of Water Level. Techniques of Water-Resources Investigations 8-A3, US Geological Survey.

Gerten D., Schaphoff S., and Lucht W., 2007. Potential future changes in water limitation of the terrestrial biosphere. Climatic Change, 80, 277-299.

Gielen B., Acosta M., Altimir N., et al., 2018. Ancillary vegetation measurements at ICOS ecosystem stations. Int. Agrophys., 32, 645-664.

Halliwell D.H. and Rouse W.R., 1987. Soil heat flux in permafrost-characteristics and accuracy of measurement. J. Climatol., 7, 571-584.

Heitman J.L., Xiao X., Horton R., and Sauer T.J., 2008. Sensible heat measurements indicating depth and magnitude of subsurface soil water evaporation. Water Resour Res., 44, W00D05.

Howard D.M. and Howard P.J.A., 1993. Relationships between $\mathrm{CO}_{2}$ evolution, moisture content and temperature for a range of soil types. Soil Biol Biochem., 25, 1537-546.

Huang P.M., Li Y., and Sumner M.E., 2011. Handbook of Soil Sciences: Properties and Processes. Second Edition. CRC Press, Boca Raton, USA.

Hukseflux, 2011. HFP01-SC Self Calibrating Heat Flux Sensor User Manual. v0811.

IGRAC, 2008. Guideline on: Groundwater monitoring for general reference purposes. Editor: Gerrit Jousma, IGRAC, The Netherlands Report nr. GP 2008-1.

ISO, 2001. ISO-11461:2001. Soil quality — Determination of soil water content as a volume fraction using coring sleeves Gravimetric method. International Organization for Standardization. Geneva, Switzerland.

Jarvis P. and Linder S., 2000. Constraints to growth of boreal forests. Nature, 405, 904-905.

Jungqvist G., Oni S.K., Teutschbein C., and Futter M.N., 2014. Effect of climate change on soil temperature in Swedish boreal forests. PloS ONE, 9, e93957.
Kellner E., 2001. Surface energy fluxes and control of evapotranspiration from a Swedish Sphagnum mire. Agr Forest Meteorol, 110, 101-123.

Kurylyk B.L., MacQuarrie K.T.B., and McKenzie J.M., 2014. Climate change impacts on groundwater and soil temperatures in cold and temperate regions: Implications, mathematical theory, and emerging simulation tools. Earth Sci. Rev., 138, 313-334.

Laurila T., Aurela M., and Tuovinen J.P., 2012. Eddy covariance measurements over wetlands. In: Eddy Covariance (Eds M. Aubinet, T. Vesala, D. Papale). Springer Atmospheric Sciences. Springer, Dordrecht, The Netherlands.

McDaniel P.A, 2006. Anaerobic processes. In: Encyclopedia of Soil Science, Volume 1 Second edition. (Ed. R. Lal). Taylor and Francis, Boca Raton, USA.

Metzger S., 2018. Surface-atmosphere exchange in a box: Making the control volume a suitable representation for in-situ observations. Agr. For Meteorol., 255, 68-80.

Mikkelä C., Sundh I., Svensson B.H., and Nilsson M., 1995. Diurnal variation in methane emission in relation to the water table, soil temperature, climate and vegetation cover in a Swedisch acid mire. Biogeochemistry, 28, 93-114.

Muñoz-Carpena R., Shukla S., and Morgan K., 2010. Field devices for monitoring soil water content. SR-IWM-2. Southern Regional Water Program.

Nagare R.M., Schincariol R.A., Quinton W.L., and Hayashi M., 2011. Laboratory calibration of time domain reflectometry to determine moisture content in undisturbed peat samples. Eur. J. Soil Sci., 62, 505-515.

Ochsner T.E., Sauer T.J, and Horton R., 2006. Field tests of the soil heat flux plate method and some alternatives. Agron. J., 98, 1005-1014.

Op de Beeck M., Sabbatini S., and Papale D., 2017a. ICOS Ecosystem Instructions for Soil Meteorological Measurements (TS, SWC, G) (Version 20180123). ICOS Ecosystem Thematic Centre. https://doi.org/10.18160/1a28-gex6

Op de Beeck M., Sabbatini S., and Papale D., 2017b. ICOS Ecosystem Instructions for Water Table Depth Measurements (Version 20180130). ICOS Ecosystem Thematic Centre. https://doi.org/10.18160/k9vq-k8d0

Peng X., Wang Y., Heitman J., Ochsner T., Horton R., and Ren T., 2017. Measurement of soil-surface heat flux with a multi-needle heat-pulse probe. Eur. J. Soil Sci., 68, 336-344.

Pregitzer K.S., King J.S., Burton A.J., and Brown S.E., 2000. Responses of tree fine roots to temperature. New Phytol., 147, 105-115.

Quinones H., Ruelle P., and Nemeth I., 2003. Comparison of three calibration procedures for TDR soil moisture sensors. Irrig. Drain, 52, 203-217.

Sauer T.J. and Horton R., 2005. Soil heat flux. In: Micrometeorology in Agricultural Systems, Agronomy Monographs 47 (Eds J.L. Hatfield, J.M. Baker). American Society of Agronomy, Madison, USA.

Schaufler G., Kitzler B., Schindlbacher A., Skiba U., Sutton M.A., and Zechmeister-Boltenstern S., 2010. Greenhouse gas emissions from European soils under different land use: effects of soil moisture and temperature. Eur. J. Soil Sci., 61, 683-696. 
Sinclair K. and Pitz C., 2010. Standard Operating Procedure for the use of Submersible Pressure Transducers During Groundwater Studies Version 1.0. - Washington State Department of Ecology - Environmental Assessment Program.

Smith K.A, Ball T., Conen F., Dobbie K.E., Massheder J., and Rey A., 2003. Exchange of greenhouse gases between soil and atmosphere: interactions of soil physical factors and biological processes. Eur. J. Soil Sci., 54, 779-791.

Stoy P.C., Mauder M., Foken T., Marcolla B., Boegh E., Ibrom A., Arain M.A., Arneth A., Aurela M., Bernhofer C., Cescatti C., Dellwik E., Duce P., Gianelle D., van Gorsel E., Kiely G., Knohl A., Margolis H., McCaughey H., Merbold L., Montagnani L., Papale D., Reichstein M., Saunders M., Serrano-Ortiz P., Sottocornola M., Spano D., Vaccari F., and Varlagin A., 2013. A data-driven analysis of energy balance closure across FLUXNET research sites: The role of landscape scale heterogeneity. Agr. Forest Meteorol., 171-172, 137-152. von Arnold K., Nilsson M., Hanell B., Weslien P., and Klemedtsson L., 2005. Fluxes of $\mathrm{CO}_{2}, \mathrm{CH}_{4}$ and $\mathrm{N}_{2} \mathrm{O}$ from drained organic soils in deciduous forests. Soil Biol. Biochem., 37, 1059-1071.

Wilson K., Goldstein A., Falge E., Aubinet M., Baldocchi D., Berbigier P., Bernhofer C., Ceulemans R., Dolman H., Field C., Grelle A., Ibrom A., Law B.E., Kowalski A., Meyers T., Moncrieff J., Monson R., Oechel W., Tenhunen J., Valentini R., and Verma S., 2002. Energy balance closure at FLUXNET sites. Agr. Forest Meteorol., 113, 223-243.

WMO, 2008. Guide to Meteorological Instruments and Method of Observation. WMO-No 8, Geneva.

Xiao X., Heitman J.L., Sauer T.J., Ren T., and Horton R., 2014. Sensible heat balance measurements of soil water evaporation beneath a maize canopy. Soil Sci. Soc. Am. J., 78, 361-368.

Zhang X., Lu S., Heitman J.L., Horton R., and Ren T., 2012. Measuring subsurface soil-water evaporation with an improved heat-pulse probe. Soil Sci. Soc. Am. J., 76, 876-879. 